\title{
Assessment of WLC and Fuzzy Logic Methods for Site Selection of Water Reservoirs in Malaysia
}

\author{
Himan Shahabi ${ }^{1 *}$, Bakhtyar Ali Ahmad ${ }^{2}$, Baharin Bin Ahmad', \\ Mohammad Javad Taheri Amiri ${ }^{4}$, Soroush Keihanfard ${ }^{5}$, Saeed Ebrahimi ${ }^{6}$ \\ ${ }^{1}$ Department of Geomorphology, Faculty of Natural Resources, University of Kurdistan, Iran \\ ${ }^{2}$ Department of Geoinformatics, Faculty of Geo Information and Real Estate, \\ Universiti Teknologi Malaysia (UTM), Malaysia \\ ${ }^{3}$ Department of GeoInformation, Faculty of Geo Information and Real Estate, \\ Universiti Teknologi Malaysia (UTM), Malaysia \\ ${ }^{4}$ Department of Construction Management, Babol University of Technology, Babol, Iran \\ ${ }^{5}$ Department of Construction Management, Tehran Science and Research Branch, \\ Islamic Azad University, Mazandaran, Iran \\ ${ }^{6}$ Department of Construction Management, Sari Branch, Islamic Azad University, Sari, Iran
}

Received: 8 February 2015

Accepted: 21 January 2016

\begin{abstract}
The purpose of this study is to compare the weighted linear combination (WLC) and fuzzy logic (FL) models in identifying the most suitable location for a water reservoir in the area of Batu Pahat, Johor, Malaysia. First of all, parameters important to a water reservoir for the studied area were identified. Then maps of the study area were prepared and integrated. The main criteria selected for this study are pipe line, elevation, rive, land use, road network, water supply network, and slope. Suitable locations for the water reservoir were selected using each model. The results of this study indicated that the FL method in the early stages had better decision-making powers for locating water reservoir sites when compared to the WLC method. The appropriate places for water reservoir construction based on two models were located to the northwest and west of the study area. The two models are validated using the Kappa index. According to the results of the validation method, the map produced by the FL method exhibits satisfactory properties in the study area. Thus, it can be concluded that the results derived from two models (WLC and FL) integrated in ArcGIS can be a useful tool in GIS analysis for the determination of suitable locations for water reservoir in the study area.
\end{abstract}

Keywords: fuzzy logic, GIS models, water reservoir, WLC, Malaysia

*e-mail: himanshahabi@gmail.com 


\section{Introduction}

The rise in urbanization and population has increased water demand. This in turn has raised the demand for new water reservoirs to meet the growing need for water [1]. To ensure a reliable and safe supply for future generations, more and more reservoirs will be required. The selection of a suitable site for a water reservoir has become extremely difficult in recent years as the proper selection of a suitable site must consider many factors, including hydrological, geological, and socio-economic parameters $[2,3]$.

A shocking statistic reveals that $70 \%$ of Malaysians utilize a greater amount of water than is necessary. At 226 litres per person per day, Malaysians take undue advantage of their abundant rainfall and water. However, this alarming trend can result in a dangerous water crisis. In 2013 a wave of water shortages and water cuts had negative impacts on the Malaysian populace. Generally, disillusionment will develop among hundreds of thousands of people whenever their access to water is truncated.

A geographic information system (GIS) can be used effectively for this purpose to combine different themes objectively and analyze them systematically for identifying suitable places [4]. In the past, many studies have been carried out using GIS for the selection of suitable sites for subsurface dams [5-8], landfill sites [9-14], hospital site selection [15-18], geothermal site selection [19-21], and more.

Also, some research has focused on water resource planning and management and hydrologic modeling using GIS modeling [22-25]. The main difference between previous studies and the present study is that there has been no comprehensive study to date involving the application and assessment of GIS-based multi-criteria analysis, including WLC and fuzzy logic methods to identify the suitable sites in a water reservoir, especially in Malaysia. The purpose of this paper is to assess and compare the results of site selection of water reservoir sites using two GIS-based multi-criteria methods, including WLC and FL models in the Batu Pahat, Johor, in Malaysia. This evaluation involves three main steps: identification of categories of the causative factors responsible for identifying possible water reservoir locations based on GIS, estimating the relative contributions of these categories in establishing a relationship between the categories and the selected sites, and validation of WLC and FL models using a Kappa index to assess the relationship between the appropriate places for water reservoir construction in the study area and causative factors.

\section{Study Area}

Batu Pahat is a town in Johor state of Malaysia. Geographically it is located between longitudes $102^{\circ} 56^{\prime}$ and $102^{\circ} 933^{\prime} \mathrm{E}$, and latitudes $1^{\circ} 51^{\prime} \mathrm{N}$ and $102^{\circ} 933^{\prime} \mathrm{N}$. The town shares borders with Pontian, Muar, and Kluang to the southeast, west, and east, respectively, and Ledang and Segamat to the north (Fig. 1). Nearly 56\% of the Batu Pahat has slope angles ranging from $0^{\circ}$ to $5^{\circ}$. The mean slope angle is $6^{\circ}$, while the maximum slope angle is $51^{\circ}$. The long-term mean monthly rainfall at Batu Pahat station is $2,057 \mathrm{~mm}$ and mean potential evaporation rate is $1,324 \mathrm{~mm}$. We used long-term rainfall and evaporation rates from a 28-year period (1985-2013) based on the

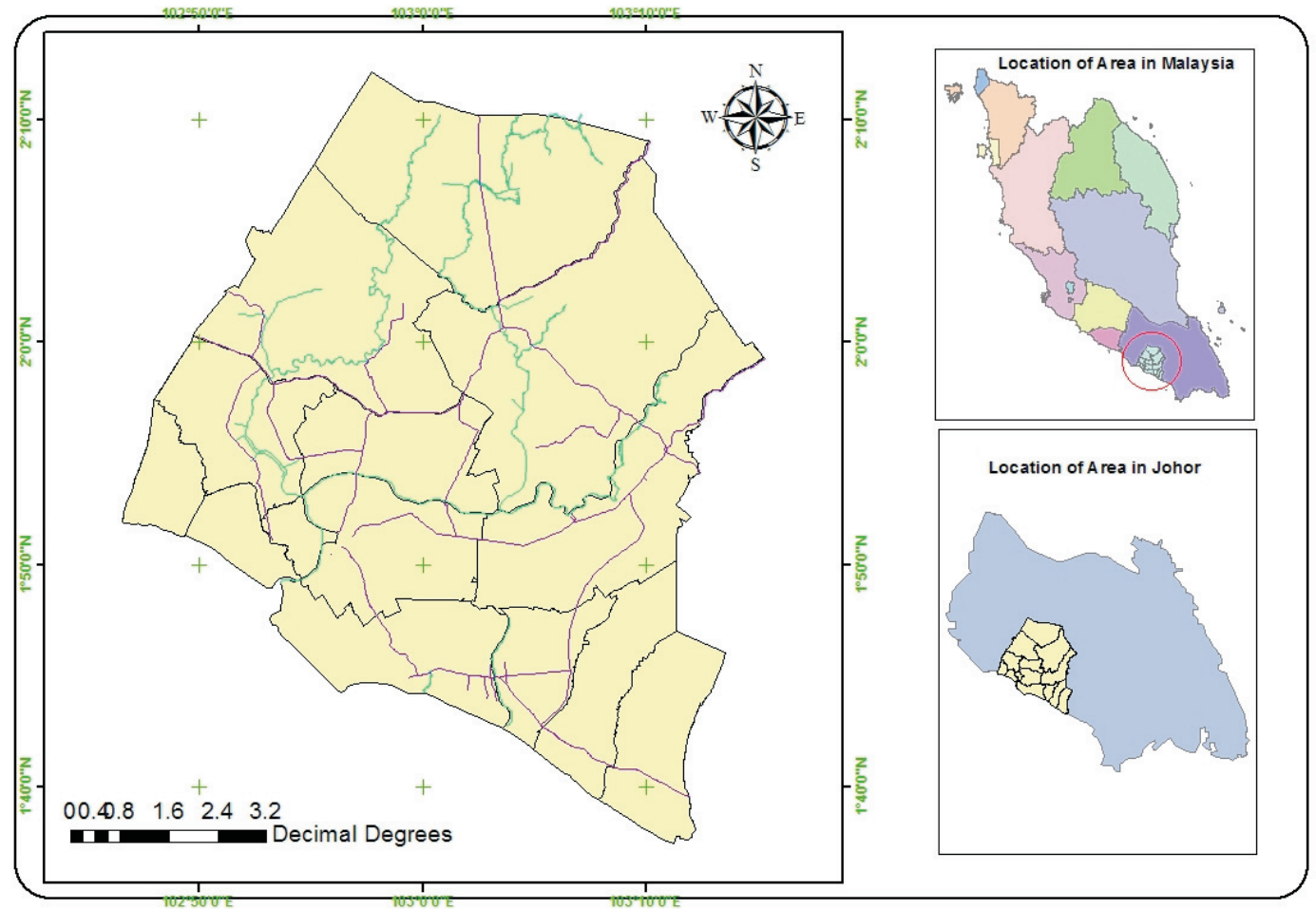

Fig. 1. Location map of the study area in the state and country. 
records from the Malaysian Meteorological Department. Also, the mean annual discharge at Batu Pahat station $\left(1.13 \mathrm{~km}^{2}\right)$ in Johor state is $21.8 \mathrm{~m}^{3} / \mathrm{s}$. The main tributaries of the Johor River are the Sayong, Linggiu, Semanggar, Tiram, and Lebam [26].

Furthermore, regarding land use of the study area that was extracted from Google Earth and a land-use map for Johor in 2010, more than $25 \%$ of the city of Batu Pahat is an area of hills covered by protected forest, 34\% of the city is residential, and the rest is effectively farmland (Fig. 2). The area of Batu Pahat is $1,999 \mathrm{~km}^{2}$ with a population of 406,000 , and is the second most populous district in Johor State. The population density is 203 per $\mathrm{km}^{2}$. The urbanization rate is related to population growth. It is projected that urbanization will be $95 \%$ in 2050 [27]. According to DID (2010), industrial and domestic water demand for Batu Pahat will rise three times from 954 million liters per day (348 million $\mathrm{m}^{3} / \mathrm{yr}$ ) in 2000 to
$31.62 \mathrm{M} / \mathrm{l} / \mathrm{d}\left(11.54\right.$ million $\left.\mathrm{m}^{3} / \mathrm{yr}\right)$ in 2050 . The normal flows during periods of severe drought can hardly meet the expected demand in 2050 of $31.62 \mathrm{M} / \mathrm{l} / \mathrm{d}$ for the study area. The water demand was 174.22 Million liters per day $(\mathrm{M} / \mathrm{l} / \mathrm{d})$ and it is projected to be $270.77 \mathrm{M} / \mathrm{l} / \mathrm{d}$ in 2050 [26].

This district is divided into 14 sub-districts known as MUKIM. Depending on the average annual population growth rate, initial population and time period of years can be determined by using the formula for population growth $\left\{\mathrm{P}=\mathrm{Poe}^{*} \mathrm{r} * \mathrm{t}\right\}$ when $(\mathrm{P})$ final population, (Poe) initial population, (r) rate of growth, and ( $\mathrm{t}$ ) time (years passed) [28]. A water supply system collects, transmits, treats, stores, and distributes water from its origin to the end users like irrigation facilities, industries, commercial establishments, public agencies, and homes. The Batu Pahat has 51 existing water reservoirs, the capacity of which is $208,687 \mathrm{M} / 1$ [26].
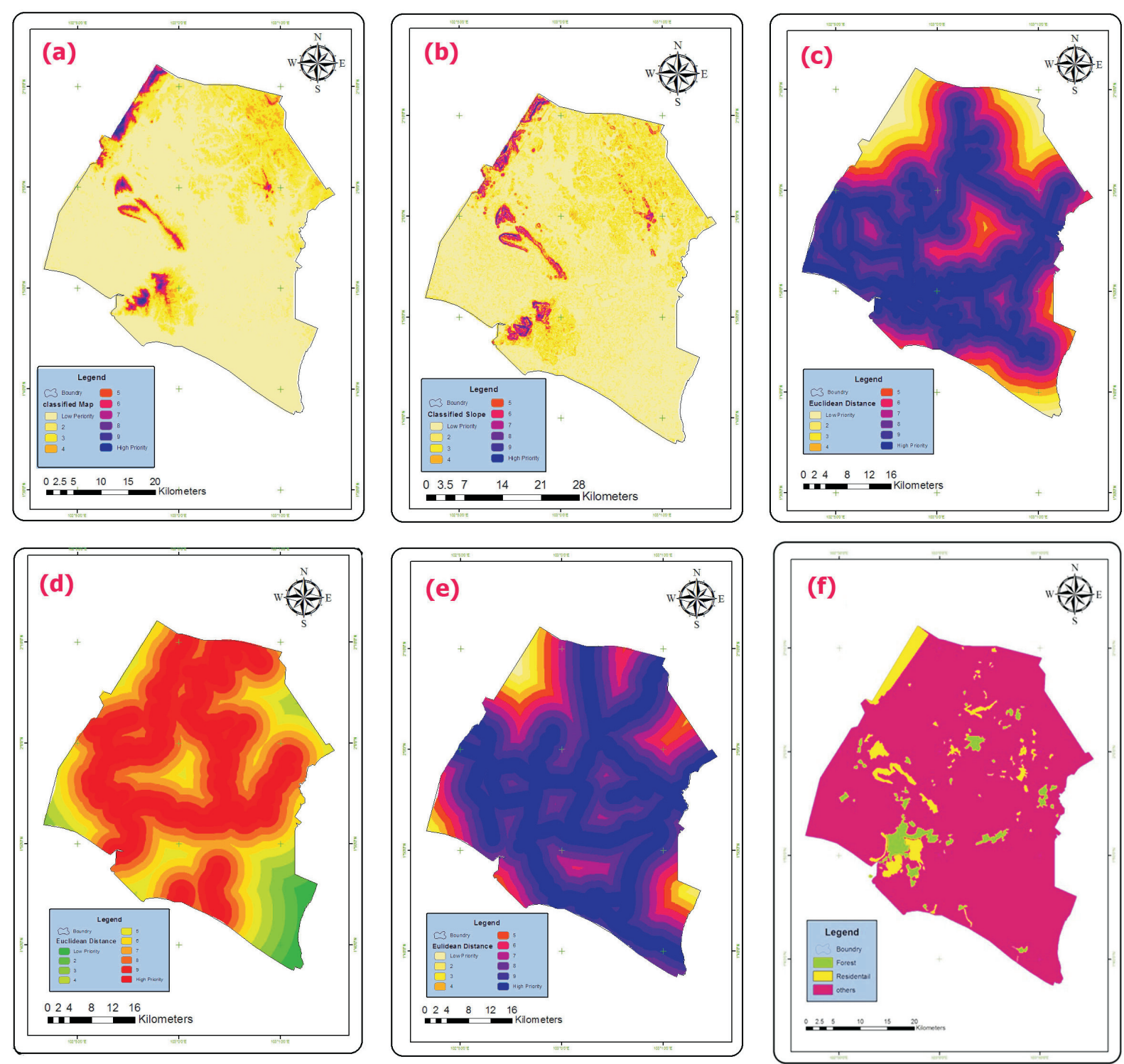

Fig. 2. The main criteria for site selection of a water reservoir: a) elevation, b) slope, c) distance to rivers, d) distance to roads, e) depth to pipelines, and f) land use. 


\section{Materials and Methods}

In the present study most of the data used came from various sources using different types of coordinate systems with different qualities. Most time is spent on data adjustments and transformation. Similarly, not all data are available for comprehensive analysis, which probably effects the results obtained in this study. Reservoir site investigations are often carried out by a team of specialists. However, it is impractical for such a team to survey all potential areas. Thus, for the reservoir site selection in the Batu Pahat district with the help of Arc GIS and AutoCAD, the input datasets are in shapefile (shp) format. Therefore, the first step is converting the layers into a geo-database and then making a new toolbox and environment setting.

In order to find a new site for a reservoir in the Batu Pahat region in Johor Malaysia, it should come up with a ranked suitability map as it shows a relative range of values specifying the suitability of each location on the map. For the creation of map distance, a special analysis tool is used in ArcGIS software, of which there are many types: path distance back link, path distance allocation, path distance, Euclidean distance, Euclidean allocation, cost path, cost distance, cost back link, cost allocation, and corridor. Euclidean distance was chosen as a tool to explain the inter-connection of individual cells and its source or a set of sources using straight-line distance [29].

The distances for each (river, road network and pipeline) are identified. These types of distance could be extremely useful for reservoir site selection. In this study, natural breaks classes are used depending on natural groupings present in the classifications of the layers. Class breaks are recognized as the best distinguished related values, and that increases the differences between classes.

In this research natural breaks classes were used based on natural groupings inherent in the data. Class breaks identify the best group similar values and that maximizes the differences between classes. These criteria were reclassified in order to make the result more accurate. The Euclidean distance output raster contains the measured distance from every cell to the nearest source. The main criteria selected for this study are: a) elevation, b) slope, c) distance to rivers, d) distance to roads, e) depth to pipelines, f) land use (Fig. 2).

In this study, two models, including weighted linear combination (WLC) and fuzzy logic (FL), were used to select sites for a water reservoir for the city of Batu Pahat.

\section{Weighted Linear Combination Method}

WLC is a hybrid between qualitative and quantitative methods based on the qualitative map combination approach (heuristic analysis). This technique is a popular method that is customizable in many GIS systems and is applicable for the flexible combination of maps. Thus the tables of scores and the map weights can be adjusted based on the expert's judgement in the domain. Firstly, this method requires the standardization of the classes in each factor to a common numeric range. Each factor rating was based on the relative importance of each class according to field observations and existing literature, indicating the conditions as highly susceptible to slope failure [14].

Primary-level weights and secondary-level weights are two types of parameters used. The primary-level weights are rule-based, whereby the ratings given to each class of a parameter are based on certain criteria. Determining the proportion for a specific operation or evaluating the potential of a particular occurrence is considered to be a desired purpose. In this method, decision-making principles calculated the value of each $A i$ option using Equation (1):

$$
A_{i}=\sum_{j=1}^{n} W_{j} \times X_{i j}
$$

...where $W_{j}$ is the $j$ criterion weight and $X_{i j}$ is a value which accepted $i$ place in relation to $j$ criterion. In other words, this value can indicate the appropriate degree of the $i$ location in relation to $j$ criterion. $n$ is the total number of criteria and $A_{i}$ is a value that will attach to the $i$ location.

In this method, the total weight should be equal to 1 ; otherwise in the last stage, $A_{i}$ should be divided by the total of all weights, thus the $A_{i}$ output will be between 0 and 1 . Higher or lower amounts of output can be due to an appropriate or inappropriate option and weight normalizing can be omitted. In the end, the ideal option will be the one that has a higher amount of $A_{i}$ [30].

In this method, the alternative with the highest overall score can select the overall scores to be calculated for all of the alternatives [31]. The final steps for site selection of a water reservoir using the WLC method is the combination of all weighted layers into individual maps. The WLC method can be performed using any GIS systems that have overlay techniques, which allow the assessment criterion map layers as input maps to be combined in order to ascertain the composite map layer as an output map.

\section{Fuzzy Logic Method (FL)}

The FL method proposed by [32] is usually utilized to manage complicated issues and employs the membership function that shows the degree of membership regarding a number of characteristics. FL is carried out using GIS modeling language for more flexible combinations of weighted maps.

The fuzzy membership value for each pixel map extracted from FL displays both the relative importance of the relative values and factors corresponding to different locations on the map area. Fuzzification of each of the effective factors using IDRISI ANDES software terminated, after which each factor was assigned a type and shape membership function. For factor maps integration some fuzzy operators, such as the fuzzy AND, the fuzzy OR, fuzzy algebraic product, fuzzy algebraic sum, and 
fuzzy gamma operator can be used. These operators are as follows [33]:

The fuzzy AND is defined as Eq. (2):

$$
\mu_{\text {combination }}=\operatorname{MIN}\left(\mu_{A}, \mu_{B}, \mu_{C}, \ldots\right)
$$

The fuzzy OR is defined as Eq. (3):

$$
\mu_{\text {combination }}=\operatorname{MAX}\left(\mu_{A}, \mu_{B}, \mu_{C}, \ldots\right)
$$

In both the above fuzzy operators (AND and OR) the $\mu_{\text {combination }}$ is the calculated fuzzy membership function, $\mu_{A}$ is the membership value for map $A$ at a particular location, and $\mu_{B}$ is the value for map $B$, and so on. Also, $M A X$ is the maximum value of any of the input maps.

The fuzzy algebraic product is defined as Eq. (4):

$$
\mu_{\text {combination }}=\prod_{i=1}^{n} \mu_{I}
$$

The fuzzy algebraic sum is defined as Eq. (5):

$$
\mu_{\text {combination }}=1-\prod_{i=1}^{n}\left(1-\mu_{i}\right)
$$

In both the above fuzzy operators (algebraic product and algebraic sum) the $\mu_{i}$ is the fuzzy membership function for the $i$ th map, and $i=1,2, \ldots, n$ maps are to be combined.

The gamma operation is defined in terms of the fuzzy algebraic product and the fuzzy algebraic sum by Eq. (6):

$$
\begin{gathered}
\mu_{\text {combination }}=(\text { fuzzy algebraic sum })^{\lambda} \\
*(\text { fuzzy algebraic product })^{1-\lambda}
\end{gathered}
$$

...where $\lambda$ is a parameter chosen in the range $(0,1)$ and the fuzzy algebraic sum and fuzzy algebraic product are calculated using Eqs. 4 and 5, respectively. In the fuzzy gamma operation, when $\lambda$ is 1 the combination is the same as the fuzzy algebraic sum, and when $\lambda$ is 0 the combination equals the fuzzy algebraic product. In addition to the scale selection process used to create fuzzy maps, other types of fuzzy functions should be investigated and more suitable functions selected for the criterion. Sigmodial, linear, and $\mathrm{J}$-shape are considered to be the most prominent functions. These functions exist in the IDRISI software [14]. In this study, the sigmoidal function was used because it was a commonly used function.

\section{Results and Discussion}

In this study, the site selection of a water reservoir was implemented using the methods of WLC and fuzzy logic operators.

\section{Site Selection of Water Reservoir Site Using WLC Model}

To be able to create a water reservoir site map using the WLC model, first the factor weights were extracted from Expert Choice software that are principally based on the ratings provided to each class of a factor on the basis of a certain criterion. In order to actualize this phase, the pair-wise comparison matrix and CR of used data layers are shown in Table 1.

In this study, the weight value of slope (0.135) and river (0.124) are the highest. On the other hand, the low WLC weights belong to a road network and elevation with 0.069 and 0.095 , respectively (Table 1 ). The CR is ascertained to be 0.061 and this value expresses the appropriate amount of CR employed to acquire the comparison matrix because it is less than 0.1 . Therefore, the weights related to factors were multiplied by the appropriate factor maps and then all the weighted factor maps were overlaid to extract a water reservoir site map based on the WLC model.

The allocated rates were used to reclassify vector data layers, and raster data layers were generated from newly reclassified data. Also, the raster calculator function was

\begin{tabular}{|c|c|c|c|c|c|c|c|}
\hline Factors & Elevation & Land use & River & Slope & Road network & Pipelines & Weights \\
\hline Elevation & 1 & & & & & & 0.095 \\
\hline Land use & 1 & 1 & & & & & 0.110 \\
\hline River & 5 & 4 & 1 & & & & 0.124 \\
\hline Slope & 2 & $1 / 2$ & $1 / 5$ & 1 & & & 0.135 \\
\hline Road network & 5 & 5 & 2 & 3 & 1 & & 0.069 \\
\hline Pipelines & 3 & 5 & $1 / 2$ & 4 & $1 / 2$ & 1 & 0.118 \\
\hline
\end{tabular}
used for reclassified raster layers as input parameters. The results of this integration were demonstrated as the final map based on the WLC method using IDRISI software (Fig. 3).

Table 1. Pair-wise comparison matrix, factor weights, and consistency ratio of the data layers.

Consistency ratio: $0.061<0.1$ (acceptable) 


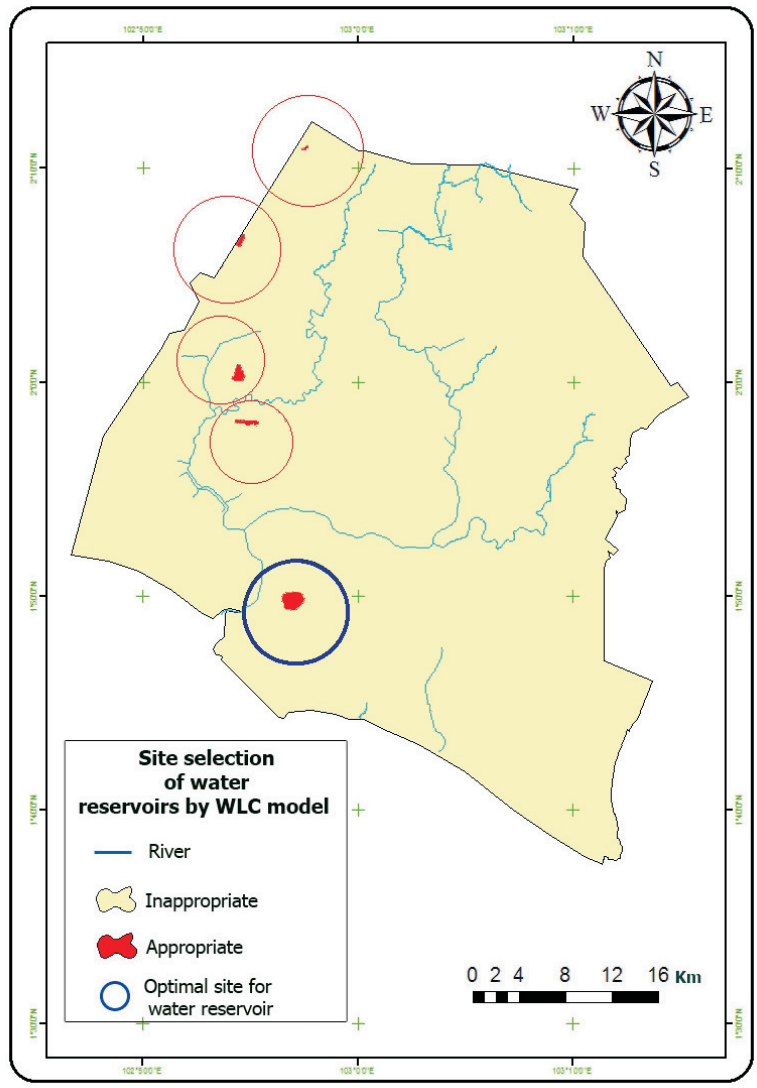

Fig. 3. Final map of water reservoir site using the weighted linear combination (WLC) method.

\section{Site Selection of Water Reservoir Site Using FL Model}

Fuzzy set theory allows an element to be a member in a fuzzy set and also a member in other fuzzy sets with different degrees of membership values [34]. The input factors were combined for assigning membership functions. Six factors to site selection of water reservoir (elevation, land use, river, slope, road network, and pipelines) were combined to generate the final water reservoir map using fuzzy operators. Different fuzzy operators provide a high level of flexibility in data integration [33]. Therefore, before the integration of data layers, they are classified on the basis of their role in the water reservoir siting (See Table 2).

Table 2. Classification of data layers for integration in water reservoir siting.

\begin{tabular}{|c|c|}
\hline Elevation & \multirow{2}{*}{ Geographical and land use } \\
\cline { 1 - 1 } Slop & \\
\hline Land use & Water resources \\
\hline River & Infrastructure \\
\hline Road network & \\
\hline Pipelines & \\
\hline
\end{tabular}

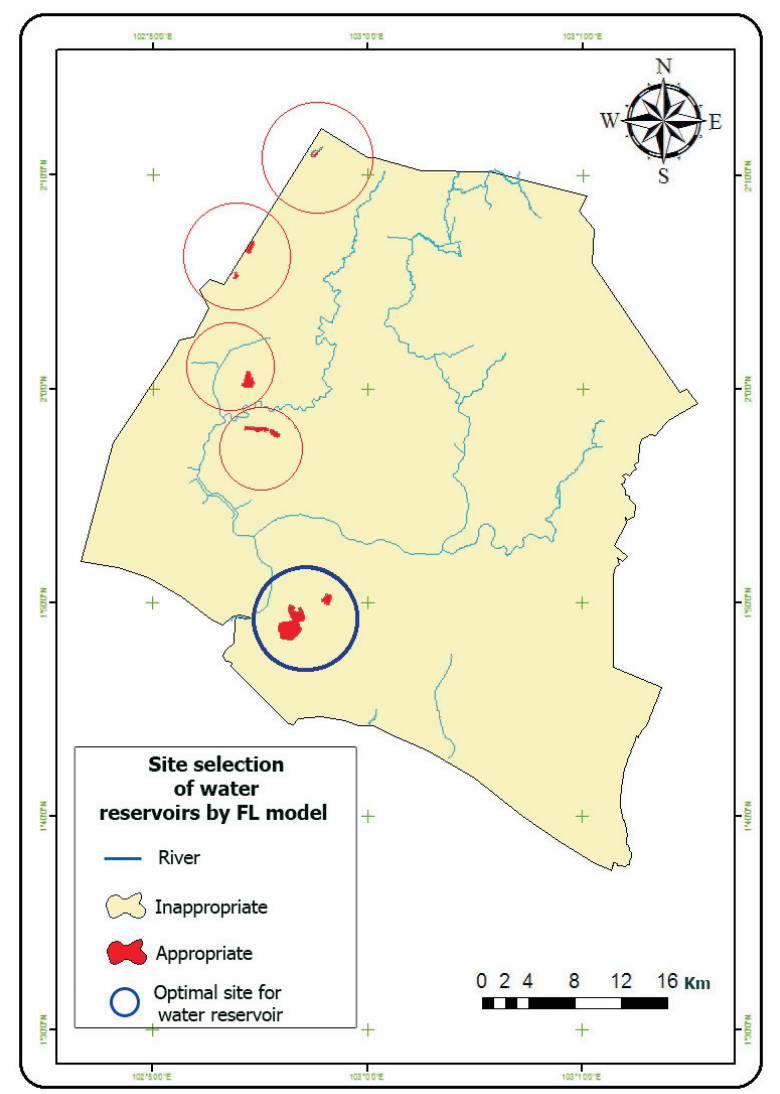

Fig. 4. Final map of the water reservoir site using the fuzzy logic (FL) method.

When using fuzzy AND and fuzzy OR operators, only one of the parameters (factor layers) is used to define the output value, which is contrary to our intention of using all factors. In this study, assuming that just one water resource is enough for water supply, the map of a river was combined using the OR operator. Using SUM and $Y>0.7$ has an increasing effect on the results so that the resulting value is larger or equal to the maximum of the input values.

For integrating elevation, slope, and land use maps, the fuzzy gamma operator was applied $(\mathrm{Y}=0.89)$. Also, the maps of pipelines and the road network were integrated using gamma operator $(\mathrm{Y}=0.7)$. At last the fuzzy algebraic sum operator was used for the final combination of fuzzy data layers. The selection of SUM and Y operators are such that a defined ratio resulted among the factors of water resources, and geophysical and land use and infrastructure on the basis of their characteristics and role in water reservoir site selection. The results of this integration were demonstrated as a final map based on the FL method using IDRISI software (Fig. 4).

\section{Selection of Suitable Locations to Water Reservoir Sites}

The result of the factor maps overlay is multiplied by the result of the limitation maps overlay. The final 


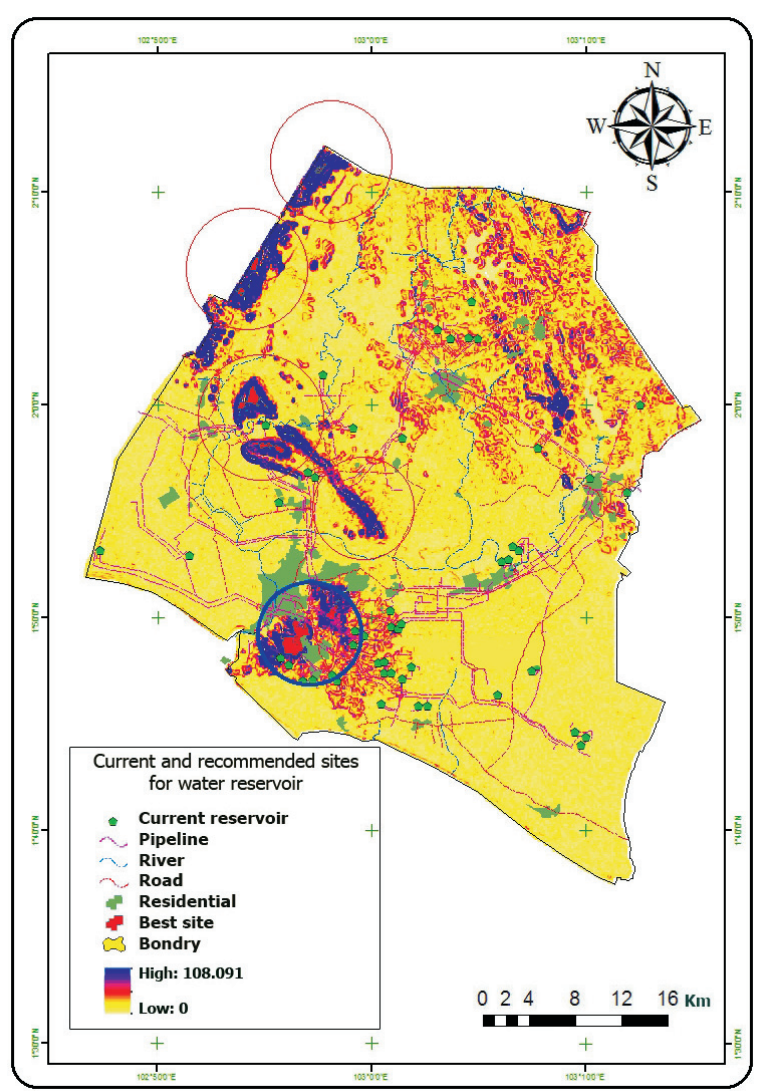

Fig. 5. Current and recommended sites for the water reservoir in Batu Pahat.

integrated maps are presented in Fig 5. In general, in WLC and fuzzy logic models, $0.14 \%$ and $0.19 \%$ of the study area was selected as suitable, respectively. The appropriate places (five sites) for water reservoir construction based on two models was located in the northwestern and western parts of the study area. Finally, the best site for a water reservoir in Batu Pahat based on overlaying the WLC and FL methods is illustrated in Fig. 5.

\section{Validation of Models Using the Kappa Method}

The site selection of a water reservoir was performed using two different approaches: the WLC and FL models. Furthermore, the analysis results were validated using the Kappa index analysis to assess the relationships between the appropriate places (five sites) for water reservoir construction in Batu Pahat and causative factors.

The validation method that was used in this study is the Kappa index (also called Khat or the Kappa index of agreement, or KIA) [35]. Cohen's Kappa index ( $\kappa)$ determines the agreement between two classifications with a nominal or ordinal scale and is calculated as [36]:

$$
K=\frac{P_{o b s}-P_{\text {exp }}}{1-P_{\exp }}
$$

...where $\mathrm{P}_{\text {obs }}$ are the observed agreements and $\mathrm{P}_{\text {exp }}$ are the expected agreements, which are calculated as:

$$
\begin{gathered}
P_{o b s}=T P+T N / n \\
P_{\text {exp }}=(T P+F N)(T P+F P)+(F P+T N)(F N+T N) / \sqrt{N}
\end{gathered}
$$

...where $n$ is the proportion of pixels that are correctly classified as appropriate sites or non- appropriate sites and $N$ is the number of total pixels.

A $\kappa$ value of 1 is obtained in the case of a perfect agreement between the model and reality, whereas a $\kappa$ value of 0 means that the agreement is no better than chance. In-between these two values, agreement changes from slight $(<0.20)$ over fair $(0.20-0.40)$, moderate $(0.40-0.60)$, substantial $(0.60-0.80)$, to nearly perfect $(0.80-1)$. The worst case (i.e., agreement is worse than chance) results in negative $\kappa$ values. It only has meaning if the categories on the two maps depict the same kind of data with the same data classes [37]. Because of this, the Kappa index value was also considered to be evidence of the similarity between the two maps. The Kappa index that measures the reliability of the models for WLC and FL are 0.8315 and 0.8736 , respectively. They indicate that a nearly perfect agreement between the models and the selected sites for water reservoirs in the study area. Finally, results showed that the FL model with Kappa index (0.8736) indicates good agreement between the model and selected appropriate sites.

\section{Conclusion}

The purpose of this study was to use several map combination methods in GIS for water reservoir siting. Future water demand is one of the key issues in water supply planning in Batu Pahat, Malaysia. It is projected that the water demand in the study area will be $206 \mathrm{M} / \mathrm{l} / \mathrm{d}$ by 2020 . Therefore, the capacity of existing intakes or structures is unable to fulfill the requirement for future use. Thus, there is a need to construct new water reservoirs to fulfill the future water demand of the study area.

In this study, the potential of methods such as WLC and FL using GIS tools have been evaluated at Batu Pahat, Malaysia, for site selection of a water reservoir. The results showed that the majority of the five suitable areas for a water reservoir was located northwest and west of Batu Pahat. Among these sites, one site was chosen as the best place for a reservoir due to many criteria being applied for this particular area. Furthermore, the analysis results obtained from the WLC and FL models were validated using the Kappa index analysis to assess the relationship between the appropriate places (five sites) for water reservoir construction in Batu Pahat and causative factors. 
The Kappa index that measures the reliability of the models for WLC and FL are 0.8315 and 0.8736, respectively. According to the results of the validation method, the map produced by the FL method exhibits satisfactory properties in the study area. Flexibility of the fuzzy method allows the user to apply a variety of data integration methods based on the characteristics of the data parts and the way they effect (support or decline) each other regarding the application. The results of this study demonstrated the ability of geographical information systems (GIS) for selecting possible water reservoir sites.

\section{Acknowledgements}

This study was conducted as part of a research university grant (Q.J130000.2527.12H65) by Universiti Teknologi Malaysia (UTM). The authors would like to acknowledge the anonymous reviewer and editor for their helpful comments on a previous version of the manuscript.

\section{References}

1. SHIKLOMANOV I.A. World water resources. Water in Crisis. New York, Oxford. 1993.

2. BARTRAM J., BALLANCE R. Water quality monitoring: A practical guide to the design and implementation of freshwater quality studies and monitoring programmes. CRC Press. 1996.

3. RAHMAN A. Application of remote sensing and gis technique for urban environmental management and sustainable development of delhi, india. In Applied remote sensing for urban planning, governance and sustainability, Springer: 165, 2007.

4. SHAHID S., NATH S., ROY J. Groundwater potential modelling in a soft rock area using a GIS. International Journal of Remote Sensing, 21, 1919, 2000.

5. RAHMAN M.A., RUSTEBERG B., GOGU R., LOBO FERREIRA J., SAUTER M. A new spatial multi-criteria decision support tool for site selection for implementation of managed aquifer recharge. Journal of environmental management, 99, 61, 2012.

6. CHENINI I., MAMMOU A.B., EL MAY M. Groundwater recharge zone mapping using GIS-based multi-criteria analysis: A case study in central tunisia (maknassy basin). Water resources management, 24, 921, 2010.

7. JAMALI I.A., OLOFSSON B., MÖRTBERG U. Locating suitable sites for the construction of subsurface dams using gis. Environmental Earth Sciences, 70, 2511, 2013.

8. KRISHNAMURTHY J., MANI A., JAYARAMAN V., MANIVEL M. Groundwater resources development in hard rock terrain-an approach using remote sensing and GIS techniques. International journal of applied earth observation and geoinformation, 2, 204, 2000.

9. ŞENER B., SÜZEN M.L., DOYURAN V. Landfill site selection by using geographic information systems. Environmental geology, 49, 376, 2006.

10. CHANG N.-B., PARVATHINATHAN G., BREEDEN J.B. Combining GIS with fuzzy multicriteria decision-making for landfill siting in a fast-growing urban region. Journal of environmental management, 87, 139, 2008.
11. SUMATHI V., NATESAN U., SARKAR C. GIS-based approach for optimized siting of municipal solid waste landfill. Waste management, 28, 2146, 2008.

12. ŞENER Ş., ŞENER E., NAS B., KARAGÜZEL R. Combining ahp with GIS for landfill site selection: A case study in the lake beyşehir catchment area (konya, Turkey). Waste Management, 30, 2037, 2010.

13. WANG G., QIN L., LI G., CHEN L. Landfill site selection using spatial information technologies and AHP: A case study in Beijing, China. Journal of environmental management, 90, 2414, 2009.

14. SHAHABI H., KEIHANFARD S., AHMAD B.B., AMIRI M.J.T. Evaluating boolean, AHP and WLC methods for the selection of waste landfill sites using GIS and satellite images. Environmental Earth Sciences, 71, 4221, 2014.

15. VAHIDNIA M.H., ALESHEIKH A.A., ALIMOHAMMADI A. Hospital site selection using fuzzy AHP and its derivatives. Journal of environmental management, 90, 3048, 2009.

16. KAISER R., SPIEGEL P.B., HENDERSON A.K., GERBER M.L. The application of geographic information systems and global positioning systems in humanitarian emergencies: Lessons learned, programme implications and future research. Disasters, 27, 127, 2003.

17. SOLTANI A., MARANDI I.Z. Hospital site selection using two-stage fuzzy multi-criteria decision making process. Journal of Urban and Environmental Engineering (JUEE), 5, 87, 2011.

18. KAR B., HODGSON M.E. A GIS-based model to determine site suitability of emergency evacuation shelters. Transactions in GIS, 12, 227, 2008.

19. NOOROLLAHI Y., ITOI R., FUJII H., TANAKA T. GIS model for geothermal resource exploration in Akita and Iwate prefectures, northern Japan. Computers \& geosciences, 33, 1008, 2007.

20. NOOROLLAHI Y., ITOI R., FUJII H., TANAKA T. GIS integration model for geothermal exploration and well siting. Geothermics, 37, 107, 2008.

21. NOOROLLAHI Y. Application of gis in exploration management and well site selection of namafjall geothermal area. North Iceland, UNU Geothermal Training Program, Report, 1, 44, 2005.

22. MCKINNEY D.C., CAI X. Linking GIS and water resources management models: An object-oriented method. Environmental Modelling \& Software, 17, 413, 2002.

23. LEIPNIK M.R., KEMP K.K., LOAICIGA H.A. Implementation of GIS for water resources planning and management. Journal of Water Resources Planning and Management, 119, 184, 1993.

24. DEVANTIER B.A., FELDMAN A.D. Review of GIS applications in hydrologic modeling. Journal of Water Resources Planning and Management, 119, 246, 1993.

25. COSKUN H.G., TANIK A., ALGANCI U., CIGIZOGLU H.K. Determination of environmental quality of a drinking water reservoir by remote sensing, GIS and regression analysis. Water, air, and soil pollution, 194, 275, 2008.

26. DID. Review of the National Water Resources Study (20002050) and Formulation of National Water Resources Policy. Jabatan Pengairan dan Saliran Malaysia, 34, 2010.

27. DOS. Basic population characteristics by districts, Department of Statistics. Department of Irrigation and Drainage (2010). Review of the national water resources (2000-2050) and formulation of natural water resources policy, Selangor Federal Territory of Kuala Lampur and Putrajaya, 42, 2010.

28. JOHNSON K.M., LICHTER D.T. Natural increase: A new source of population growth in emerging hispanic 
destinations in the united states. Population and Development Review, 34, 327, 2008.

29. CERCHIAI B., FIORE G., MADORE J. Geometrical tools for quantum euclidean spaces. Communications in Mathematical Physics, 217, 521, 2001.

30. MALCZEWSKI J. GIS and multicriteria decision analysis. Wiley. 1999.

31. SHAHABI H., HASHIM M. Landslide susceptibility mapping using GIS-based statistical models and Remote sensing data in tropical environment. Scientific Reports, 5, $1,2015$.

32. ZADEH L.A. Fuzzy sets. Information and control, 8, 338, 1965.

33. SHAHABI H., HASHIM M., AHMAD B.B. Remote sensing and gis-based landslide susceptibility mapping using frequency ratio, logistic regression, and fuzzy logic methods at the central zab basin, iran. Environmental Earth Sciences, 73, 8647, 2015.

34. DUBOIS D., PRADE H. Rough fuzzy sets and fuzzy rough sets. International Journal of General System, 17, 191, 1990.

35. CARSTENSEN L.W. A. Measure of similarity for cellular maps. The American Cartographer, 14, 345, 1987.

36. COHEN J. Weighted kappa: Nominal scale agreement provision for scaled disagreement or partial credit. Psychological bulletin, 70, 213, 1968.

37. GRINAND C., DOMINIQUE A., BERTRAND L., MANUEL P.M. Extrapolating regional soil landscapes from an existing soil map: sampling intensity, validation procedures, and integration of spatial context. Geoderma, 143, 180, 2008. 